\title{
De Estradas e Súditos: turismo e cidadania em uma comunidade tradicional de Minas Gerais
}

\section{On Roads and Subjects: tourism and citizenship in a traditional community of Minas Gerais}

Jorge Renato Lacerda Arndt ${ }^{1}$

Solange Maria Pimenta ${ }^{2}$

\begin{abstract}
Resumo
O artigo discute as possibilidades de desenvolvimento, por meio do turismo, em Milho Verde, Minas Gerais. Remanescente da exploração de minerais preciosos da região de Diamantina, a pequena localidade inseriu-se na demanda turística contemporânea trazendo estruturas tradicionais - sociais, culturais e econômicas - em grande medida inalteradas, preservadas pela depressão das atividades econômicas no Vale do Jequitinhonha após o declínio da mineração. Já confrontada por uma série de impactos ecológicos, culturais e urbanísticos relacionados à visitação turística, a comunidade, junto com os empreendimentos informais de turismo estabelecidos pela população, está sendo incorporada a um contexto ampliado e intensificado de solicitações externas, determinado pela implementação de propostas planificadas de fomento à atividade turística - o Prodetur NE II e o roteiro de atrações históricas, culturais e ecológicas Estrada Real. Contemplando a necessidade de manutenção de condições comunitárias e ecológicas que perpetuem a atratividade turística, o artigo avalia o papel da autonomia sociopolítica local como requisito para a consecução de uma proposta de desenvolvimento.
\end{abstract}

Palavras-chave: desenvolvimento sustentável; turismo social; Estrada Real; Prodetur NE II; turismo solidário.

\begin{abstract}
The article discusses the possibilities of development, by means of the tourism, in Milho Verde community, State of Minas Gerais, Brazil. A remaining of the exploration of precious minerals in the region of Diamantina, the small locality was inserted in the contemporary touristic demand bringing traditional structures - social, cultural and economic - largely unaltered, preserved by the depression of the economic activity that affected all the Jequitinhonha Valley after the decline of the mining activity. Already confronted to a series of ecological, cultural and urbanistic impacts related to the touristic demand, the community, with the informal enterprises in tourism established by the population, is now being incorporated to an enlarged and intensified context of external requires, determined by the

\footnotetext{
${ }^{1}$ Mestre em Administração pelo Curso de Mestrado Profissionalizante da Faculdade de Estudos Administrativos de Minas Gerais - FEAD-MG - Centro de Gestão Empreendedora. E-mail: j.arndt@lutbrasil.com.br

${ }^{2}$ Doutora em Sociologia pela Université de Paris I, Panthéon Sorbonne. Professora e pesquisadora do Curso de Mestrado Profissionalizante em Administração da Faculdade de Estudos Administrativos de Minas Gerais - FEAD-MG - Centro de Gestão Empreendedora. E-mail: solange@face.ufmg.br
} 
implementation of planned proposals of touristic activity - the Prodetur NE II and the route of historical, cultural and ecological attractions Estrada Real ("Royal Road"). Appraising the necessary maintenance of communitarian and ecological conditions that perpetuates the touristic attractiveness, the article evaluates the importance of the local sociopolitical autonomy as an essential condition to the consecution of a development proposal.

Keywords: sustainable development; social tourism; Estrada Real; Prodetur NE I; solidary tourism.

\section{Introdução}

Milho Verde, pequena sede de distrito no município do Serro, vizinha da nascente do rio Jequitinhonha, surgiu da lavra de minerais preciosos no início do séc. XVIII. De aspecto e modo de vida tradicionais, com casario e igrejas antigas cercados de montanhas de pedra e cachoeiras da Serra do Espinhaço e afastada da velocidade e tecnologia do mundo moderno, veio a se tornar um dos mais vívidos cartões-postais de Minas Gerais, sendo muito visada pela atividade turística e atraindo um grande número de novos moradores, com impactos diversos para a população local. Distante poucos quilômetros de Diamantina, integra roteiros turísticos de cunho histórico, cultural e ecológico como o da Estrada Real. Encontra-se, entretanto, pouco equipada para satisfazer os critérios de consumo geralmente associados aos padrões globalizados de atividade turística. Não possui hotéis, cafés, museus, casas culturais, bancos e comércio. As pousadas são simples e a atividade noturna é restrita a alguns poucos bares e restaurantes.

A disparidade entre o baixo desenvolvimento local - em uma região em que a sociedade estrutura-se ainda segundo moldes econômicos e culturais tradicionais - e a atividade turística - que vincula a comunidade a um panorama ampliado de processos sócio-econômicos - foi o contexto determinante de fenômenos enfocados pelo estudo de caso que embasou o presente artigo. ${ }^{3}$

Apresentada na dissertação de mestrado em Administração Entre tradição e modernidade: sustentabilidade do desenvolvimento pelo turismo em uma comunidade tradicional de Minas

\footnotetext{
${ }^{3}$ A extração de minerais preciosos, origem de grande parte dos núcleos coloniais em Minas Gerais, encontra-se hoje esgotada. Embora turisticamente atrativas, graças a seu rico legado histórico-cultural e à bela natureza do entorno, muitas localidades herdaram condições econômicas precárias e não encontraram atividades substitutas relevantes. A carência pode ser indicada mesmo em âmbitos regionais: o Vale do Jequitinhonha como um todo, por exemplo, a partir do declínio da mineração, desvinculou-se dos eixos econômicos mais ativos do país.
} 
Gerais (Arndt, 2007), ${ }^{4}$ a pesquisa, empreendida ao longo de 2006 e 2007, demandou uma abordagem etnográfica, em que se empregaram observações participantes e entrevistas.

Do distrito de pouco mais de 1.000 habitantes, aproximadamente metade vive na área urbana (Piva et al, 2007), onde foram instaladas, ao longo dos últimos vinte anos, luz elétrica e telefonia fixa e celular, serviços que ainda não atingem a zona rural. $O$ turismo gera diretamente, em pousadas, bares e restaurantes, por volta de 60 empregos informais. Praticamente todas as famílias têm uma atividade dirigida às demandas dos turistas, entre casas de aluguel, hospedagem domiciliar, venda de produtos culinários e prestação de serviços como os de construção e manutenção doméstica. Mesmo nos estabelecimentos comerciais destinados às demandas cotidianas da população, o turismo participa em proporções significativas das vendas.

As oportunidades de geração de renda pelo turismo em Milho Verde dão-se em condições de informalidade que dizem respeito a grande parte da conjuntura da implementação de projetos de desenvolvimento pelo turismo no Brasil contemporâneo. Nesse contexto, torna-se importante discutir, nos temas interarticulados de trabalho, comunidade e cidadania, como a miríade de pequenos empreendimentos situados nos destinos turísticos está se estruturando e posicionando. Deve-se considerar o interesse do tema para pesquisadores, consultores e gestores em turismo, organizações privadas, públicas e do Terceiro Setor atuantes em localidades onde o turismo afete significativamente o modo de vida e a economia locais, bem como para as comunidades em seu geral, dado o impacto que a crescente atividade turística já tem representado e irá cada vez mais representar. Como estas organizações e comunidades não se estruturam em um espaço econômico abstrato de demandas por serviços, a adequada compreensão da inserção social do empreendimento local deve ser vista como um requisito para a consecução de um desenvolvimento sustentável.

\section{De Veios e Estradas}

Por ocasião da notificação à Coroa portuguesa da descoberta do diamante nas lavras de ouro do Arraial do Tejuco (hoje Diamantina), em 1726, toda a região da Capitania das Minas já consistia um território permanentemente vigiado, a que se aplicavam regulamentos

\footnotetext{
${ }^{4} \mathrm{O}$ estudo empreende uma análise da temática do turismo em Milho Verde sob o prisma da modernização, racionalização e globalização da sociedade. Discute também a atuação de organizações do Terceiro Setor, enfocando a inserção sociopolítica de entidades presentes na região, e aborda a polêmica acerca da noção de sustentabilidade com relação à conjuntura de desenvolvimento econômico em comunidades tradicionais. $\mathrm{O}$ trabalho encontra-se disponível em http://www.fead.br.
} 
específicos, taxas, penalidades e restrições desde a primeira descoberta do ouro (Luna, 1980). Mas as dificuldades do controle da mineração de diamantes determinaram a implantação de um regime administrativo de exceção, o Distrito Diamantino, configurado territorialmente a partir de $1734 .{ }^{5}$ Visando impor exclusividade e rígida inspeção para a exploração da jazida, a administração diamantina era mantida por meio de repressão e arbitrariedade - aplicadas, por vezes, a par de abusos patrimonialistas e da conivência com o contrabando e a mineração ilegal (Souza, 1999, 1997; Furtado, 1996).

No âmbito oficial, a atividade de mineração dos diamantes era desempenhada pelo trabalho escravo. Em um primeiro momento, proprietários dessa mão-de-obra foram contratados para os empreendimentos de lavra e escavação, etapa que foi denominada a Intendência dos Diamantes, ou o Contrato, vigente desde o início da exploração, em 1740. Durante o período subseqüente, o da Real Extração, iniciado em 1772, as tarefas de mineração passaram a ser diretamente administradas pela Coroa, em um monopólio que empregava parte da população livre do Distrito e que também alugava dos habitantes locais o grande contingente de escravos utilizado. A Real Extração prolongou-se até à época do Império, findando somente em 1841.

Clandestinamente, a mineração era praticada nos recônditos do Distrito Diamantino por escravos fugidos, escravos forros, mestiços de variadas etnias, colonos brasileiros de ascendência ibérica e aventureiros portugueses, sendo esta a composição heterogênea de bandos proscritos continuamente perseguidos por tropas de dragões montados e por caçadores de escravos fugidos - os capitães-do-mato (Santos, 1976). A ilegalidade consistia, em muitos casos, um imperativo de sobrevivência para habitantes locais que, proibidos de minerar, haviam sido privados da única atividade econômica que justificara a colonização da região (Souza, 1997). ${ }^{6}$

A despeito da pequena disponibilidade local de solo favorável, os registros apontam para uma atividade regular de plantio em Milho Verde, desde os primórdios coloniais até aproximadamente meados do séc. XX (Santiago, 2006). Raro sítio fértil da região, há de ter

\footnotetext{
${ }^{5}$ Em sua configuração inicial, a Demarcação Diamantina compreendia uma área mais ou menos elíptica de aproximadamente $80 \mathrm{~km}$ no sentido norte-sul e $50 \mathrm{~km}$ no sentido leste-oeste, tendo o Tejuco ao centro (e Milho Verde na orla sudeste). Incluía também o leito e as margens do Jequitinhonha, desde a nascente até à Capitania da Bahia. Em 1745, esta Demarcação foi ampliada, estando já àquele momento proibidas a livre entrada e residência no Distrito. Estes limites ainda seriam expandidos para incorporar novos achados de leitos mineríferos e visando também isolar a região, dificultando o contrabando (Santos, 1976).

${ }^{6}$ A designação "garimpeiro", antes indicativa dos mineradores ilegais ("grimpa" era o nome dado aos refúgios acidentados de que se utilizavam na fuga ao alcance da polícia montada), terminou passando ao vernáculo como sinônimo de minerador de aluvião em geral (Mata Machado Filho, 1985; Saint-Hilaire, 1974).
} 
sido demandada, talvez desde os primeiros tempos do Tejuco aurífero, para o suprimento dos arraiais mineradores situados mais ao norte. Havia também a conveniência do sítio com vistas à fiscalização, militarmente exercida, sobre o trânsito no caminho oficial e sobre vias clandestinas de acesso à região dos diamantes. Um destacamento militar sediado em Milho Verde se beneficiaria de uma ampla visibilidade para as serranias, em todas as direções, e de uma ágil intercepção de passagens proibidas situadas ao sul e ao norte. Abrigou-se ali, portanto, a partir de 1732, um assim denominado registro, misto de quartel policial e controle alfandegário, fiscalizador da entrada e saída do Distrito Diamantino. Como em uma fronteira entre países, o acesso oficial ao Distrito era feito mediante, exclusivamente, a passagem por este único posto de controle (Mawe, 1978; Spix e Martius, 1981).

Distantes, porém, não mais de dez quilômetros do antigo arraial, constando como indícios contrários ao esperado em um contexto de forte repressão à clandestinidade, encontram-se hoje aglomerados rurais remanescentes de antigos quilombos (Baú e Ausente). Vários autores apontam os quilombos, bem como os componentes negros e mestiços de toda a população colonial da Capitania das Minas Gerais, como o principal suporte social e operacional para as atividades de mineração clandestina (Souza, 1999; Furtado, 1996; Mata Machado Filho, 1985; Saint-Hilaire, 1974).

O tráfico de diamantes, além de vantagens financeiras, possuía um sentido político de transgressão (Starling, 2004), em resposta ao monopólio e à asfixia tributária, e o cotidiano dos que viviam no interior do Distrito gradualmente se entrelaçou à prática da mineração clandestina e do contrabando. O uso da extra-oficialidade, da informalidade e da dissimulação parece haver se mesclado a demais traços culturais transmitidos pelas gerações e é procedente indagar onde esses caracteres poderiam ser observados ainda hoje (Furtado, 1996; Mawe, 1978; Saint-Hilaire, 1976; Spix e Martius, 1981). Há que se indicar também a transitoriedade intrínseca à atividade da mineração, praticada sempre conforme o espírito colonial predominante, com propósitos de ganho imediato. A esta imediatez e transitoriedade some-se a instabilidade determinada pela própria extorsão fiscal, sujeita a recrudescimentos imprevisíveis, e a inserção social precária dos extratos intermediários frente à impermeabilidade da estrutura sócio-econômica hegemônica, oficial. ${ }^{7}$ A mentalidade

\footnotetext{
${ }^{7}$ Como salienta Mello e Souza, os estudos da vida e dos costumes coloniais brasileiros demonstram que as estratégias de resistência social eram gradativamente construídas dentro do universo das práticas cotidianas (1999; Santos, 1976). A despeito da repressão, subsistiam o garimpo e o contrabando, muito em razão das necessidades de inserção econômica de camadas sociais que não as de senhores e escravos. Aos poucos surgiam os integrantes para a composição de toda uma nova sociedade colonial, que gradativamente se enraizava,
} 
imediatista de utilização dos recursos naturais, bem como, por assim dizer, a inacessibilidade dos "recursos sociais" - a indisponibilidade da cidadania - podem haver modelado, em um tal contexto, uma cultura "extrativista", não comprometida com um vínculo social institucionalizado - não cidadã.

Um entrevistado, empreendedor de turismo radicado há aproximadamente dez anos na região, associa o imediatismo, a clandestinidade e a dissimulação a uma resistência cultural regional à agregação e à composição de esforços coletivos e de cooperação:

[...] a comunidade é muito desunida [...] as pessoas não têm a capacidade de se organizarem e tratarem questões de forma cooperativa, coletiva... [...] elas não se agregam. [...] Não são cooperativas, porque querem cada um pra si. Isso mostra essa mentalidade garimpeira, eu acho. Quer ganhar. - "Tirei o meu." Eu acho que tem isso no caráter, no psicológico desse coletivo, dessa região, tem um pouco disso. E que é desagregador no sentido de se pensar coisas corporativas, coisas que primeiro a gente vai tirar, cada um tirar do bolso, tirar de si, colocar um pouco no balaio, pra depois colher o fruto.

Ao contrário do que ocorreu aos veios auríferos, as lavras adamantinas perdurariam com um certo vigor para além dos tempos coloniais e, com elas, a centralidade de Diamantina na economia regional. Após a interrupção definitiva das atividades da Real Extração, em 1841, a mineração receberia ainda um grande impulso: a acorrida à região de novas levas de mineradores independentes, empenhados em explorar com maior acurácia territórios que o monopólio da Coroa havia dado por exauridos. A população de Diamantina aumentou de 12.354 habitantes em 1832 para 30.412 em 1890 e a demanda de abastecimento por produtos agropecuários provindos dos arredores elevou-se proporcionalmente (Martins, 2000, 2004; Mata Machado Filho, 1980).

A rigor, até os presentes dias, a mineração de diamantes não se encontra completamente esgotada e somente foi considerada contraproducente após um "longo crepúsculo" durante o séc. XX (Santiago, 2006). Perdeu, porém, a posição de eixo da economia regional após uma acentuada queda nos preços internacionais do diamante, ocorrida por volta de 1860, em função da exploração por ingleses de jazidas descobertas na África do Sul. Depois dessa queda, e após aproximadamente uma década em crise, Diamantina aos poucos reacomodou sua economia em atividades de indústria e comércio. Essa resposta proveio das elites políticas

esgueirando-se por entre as brechas do sistema, operando à revelia dos esforços de fiscalização do Estado (vide a respeito Meneses, 2000, e Furtado, 1996). 
e administradoras públicas diamantinenses, que promoveram a alocação do capital minerador, e da abundante mão-de-obra disponibilizada mais tarde pela Abolição, em tecelagens e em uma série de pequenas manufaturas e indústrias leves.

Diamantina consolidou-se então como o pólo de comércio para todo o Nordeste mineiro, centralizando e abastecendo de produtos as rotas regionais. Passando por Milho Verde em direção a Diamantina, tropas de burros comunicavam todo o Vale do Jequitinhonha e outras regiões mais ao norte com os centros econômicos ao sul. Com o passar dos anos, porém, não somente este antigo caminho estaria obsoleto, mas também toda a logística do transporte tropeiro que sustentava o monopólio regional comercial e industrial de Diamantina. ${ }^{8}$

A atividade agrícola em Milho Verde manteve-se próspera enquanto não se modificaram as rotas e meios de transporte, desarticulando o mercado regional de abastecimento. Além disso, o reavivamento das lavras diamantinas pela mineração independente estendeu-se também ao território de Milho Verde e de seus arredores. Assim, tanto pela agricultura como pela mineração, a pequena localidade encontrava-se vinculada ao pólo comercial diamantinense. Descaracterizado o papel de Diamantina como pólo regional, toda a antiga área de influência da cidade terminou não incluída nos planejamentos econômicos dos anos 40, 50 e 60; o Vale do Jequitinhonha foi relegado, a partir de então, à condição de região deprimida economicamente e reservatório de mão-de-obra para a modernização econômica do centro de Minas Gerais (Martins, 2000). Reforçou-se assim, ainda mais, a emigração da população rural, "marca constante do Vale do Jequitinhonha" (Galizoni, 2000), já fortemente manifestada desde finais do séc. XIX e início do XX (com destino, então, principalmente às zonas cafeeiras de São Paulo, Paraná, e Zona da Mata e Sul mineiras - Martins, 2000; Matos, 2000, 1990).

Retroativamente com relação aos processos de transformação social encetados no contexto minerador urbano colonial, consolidou-se no Vale do Jequitinhonha uma estrutura sociopolítica de senhores rurais e camponeses, principiada no séc. XVIII e antepassada do ainda contemporâneo coronelismo. No Jequitinhonha, como em outras regiões do Nordeste e

\footnotetext{
${ }^{8}$ Este "Grande Empório do Norte", como Diamantina foi alcunhada em seu apogeu comercial e industrial, manteria a vitalidade até aproximadamente a década de 1950, quando a implementação da Rio-Bahia (BR 116) desarticulou, por fim, a antiga rede de transporte regional. Assim, devido aos seus "limites estruturais", a partir de 1940 a cidade iniciou um rápido processo de desindustrialização: já à década de 60, quase nenhuma das fábricas e pequenas manufaturas permaneceria ainda em operação. Marcos Lobato Martins (2000) vai ao fulcro da questão: "A atividade intensa das tropas em torno de Diamantina [...] deve ser apreendida como uma bem preservada persistência do antigo sistema colonial de circulação. O que significa que o Vale do Jequitinhonha ainda era um encravamento histórico-geográfico, um espaço tempo parcialmente comunicante que se desligava das estruturas fundamentais do passado muito lentamente."
} 
Centro brasileiros, essa extemporaneidade, ao invés de ser superada por uma crescente urbanização e modernização, prevaleceu e persistiu. A marca deixada pelo poder senhorial em Milho Verde é um dos traços formacionais mais relevantes, dada a influência recente sobre diversos aspectos da vida comunitária. O esgotamento da economia local restringiu a autonomia dos habitantes, tornando possível o estabelecimento de um monopólio comercial por parte dos senhores locais. A venda de víveres, o emprego da mão-de-obra rural e o transporte motorizado para Diamantina ou Serro se davam quase exclusivamente através dos meios disponibilizados por estes proprietários de terra. $\mathrm{O}$ acesso das populações rurais às instituições públicas era intermediado e, assim, utilizado como instrumento de coação. Somente se revogou este cenário com a chegada do turismo, que trouxe novas alternativas de inserção econômica. Gradualmente, a renda direta e indireta provida pelo turismo atingiu uma grande parte da população. Entre as transformações econômicas, políticas e sociais locais associadas ao turismo, a emancipação figura como um resultado marcadamente positivo e reconhecido pela população. Um habitante de Milho Verde manifestou-se com relação à superação da dominação tradicional na comunidade e às seqüelas remanescentes:

\begin{abstract}
Ah, eu acho que Milho Verde sempre foi muito preso. Desde quando eu me entendo por gente já conheço Milho Verde assim - "Ah, que Milho Verde sempre foi mandada." É que tinha uns coronéis aqui que mandavam no povo. Então o povo ficou muito preso [...] Ficou travado e nunca teve oportunidade de lutar. [...] Então, fica aqui um povo muito sem iniciativa.
\end{abstract}

O conjunto das modificações econômicas e sociais atravessadas por Milho Verde ao longo do séc. XX pode ser ilustrado pela metáfora de uma hibernação, estabelecida a partir da estagnação e intensa emigração, chegando ao perigeu econômico e populacional em aproximadamente 1970. Nesse momento, a economia local constituía-se de esparsas atividades de mineração, que seriam ainda reavivadas, durante um breve período, pelo uso de dragas (proibidas em 1989). Estava a ocorrer um crescente desmatamento das fazendas, destinando-se a lenha obtida às carvoarias e os terrenos à pecuária. A quase totalidade da população remanescente praticava então uma economia de subsistência, possível mesmo aos habitantes urbanos, graças à configuração dispersa das casas: cada quintal, com seu pequeno plantio, horta, pomar e criação de animais assegurava, por si só, grande parte das necessidades de alimentação de uma família. Assim, estava caracterizada uma peculiar "cidade-roça" isolada, por força das circunstâncias geográficas, logísticas e econômicas, das transformações 
culturais, políticas e tecnológicas da sociedade (Matos, 1990). Esse caráter de "ilha no tempo", ao mesmo tempo atrativo e frágil face às movimentações do turismo que viriam a ocorrer, foi vividamente caracterizado no trecho de entrevista que segue, transcrito do depoimento de um empreendedor de turismo imigrado para a localidade nos anos 90:

Olha, de ter vindo pra cá e vivido a passagem do milênio aqui, sempre achei que nós estamos entrando no século XXI enquanto aqui não saiu nem do século XIX ainda, nem do XVIII.

\title{
3. Um Turismo Espontâneo
}

Em 1981, uma anônima igrejinha estampada na capa de um álbum fonográfico de Milton Nascimento suscitou a curiosidade de onde se localizaria aquele cenário de uma Minas primitiva, perdida em outras eras, mas presente naquela imagem e, portanto, ainda existente e acessível. Segundo comentários dos habitantes, data mais ou menos das visitas do artista e da divulgação resultante o surgimento do turismo na localidade e a decorrente reativação econômica:

\begin{abstract}
Milton foi o seguinte: ele veio aqui e fotografou a capela [Igreja do Rosário] e pôs na capa do disco. Pôs na capa do disco e não deu o endereço, depois veio um repórti aí e fez uma reportagem [...] e deu o endereço. Ah, pronto. Não deu outra: a hora que o pessoal pegou a chegar aqui melhorou tudo. Aqui não tinha nada, estava acabando, o povo estava todo indo embora. Se não fosse o turismo aqui, pode esquecer que não melhora, não.
\end{abstract}

Inicialmente acampado em locais públicos, o turista foi aos poucos requerendo pequenos serviços da população: refeições, hospedagem em quartos familiares, consumo nos bares. Assim, deu-se início a um aquecimento do comércio local e à composição de meios de hospedagem, alimentação e lazer. Em parte dos casos, estes meios foram instituídos por imigrados que, aos poucos, radicavam-se na localidade. Em sua maioria, entretanto, os serviços ao turismo foram empreendidos por pessoas nascidas na localidade ou na região: áreas de camping, restaurantes, bares, comércio e casas e cômodos de aluguel. Fortemente sazonal e de baixo valor agregado, este primeiro turismo não solicitava a adequação dos serviços prestados - basicamente, hospedagem e alimentação - a nenhum critério de consumo externo aos padrões locais. O foco do interesse era voltado, ou pelo menos se adequava, aos costumes simples locais, que também compunham a atratividade local, juntamente com o 
cenário deslumbrante, o aspecto tradicional intocado da área urbana e a farta disponibilidade de passeios em cachoeiras, matas, campos, rios e montanhas.

A população foi sendo cada vez mais impactada por uma verdadeira avalanche de novos usos, comportamentos, referências e valores. $O$ trecho de entrevista transcrito a seguir é emblemático:

[...] tem vinte anos que tem banheiro em Milho Verde. Há vinte anos atrás, todo mundo cagava no quintal. Não tinha preocupação de construir banheiro. Com o contato com o mundo externo, então as pessoas adquiriram noções básicas de higiene. Com o contato com as pessoas que vêm de fora, começaram a se desenvolver questões como leitura, cultura, ecologia [...] Então as pessoas ganham algumas coisas, porque elas começam a conviver com o novo.

Dada a fraca articulação comunitária, a distância entre os universos culturais e econômicos de imigrados e naturais e a baixa densidade de ocupação urbana, a imigração compôs-se, em grande parte dos casos, de pessoas que não interagiram mais profundamente com a população original. Mesmo assim, ao abrir espaço para abrigar novos habitantes, permanentes ou temporários, a antiga conformação aldeã foi-se alterando, descaracterizando os atrativos urbanos e arquitetônicos e compondo, com o passar dos anos, um crescimento desordenado rumo à periferia. Criou-se toda uma nova série de problemas tais como abastecimento de água, ocupação de áreas de preservação e traçado de ruas e arranjo urbano desarmônicos com relação às necessidades cotidianas da população e em relação à manutenção da atratividade turística. O padrão de ocupação dos terrenos modificou-se e, com ele, a própria economia familiar: os grandes quintais estão aos poucos desaparecendo, sendo fracionados para atender aos compradores de imóveis e para abrigar novos prédios destinados aos hóspedes turísticos e a novos núcleos familiares (retidos na localidade graças às possibilidades econômicas providas pelo turismo).

Atraído pelos confortos de energia elétrica, telefonia, comércio e transporte e pela oportunidade de adesão à economia do turismo, também o habitante rural emigrado se incorpora ao quadro de crescimento urbano local. Delineia-se, assim, um abandono das antigas formas de subsistência em prol de uma vinculação, cada vez mais generalizada e pronunciada, à economia do turismo. Mesmo sazonal, o turismo instituiu hábitos que desestimularam a atividade de plantio, criando indisponibilidade de mão-de-obra na lavoura e reforçando a tendência, já quase plenamente manifesta, de destinação dos terrenos do entorno 
à pecuária. Criado em regime extensivo, não requerendo grandes cuidados, o gado passa a ser visto como fonte de renda complementar e como investimento acessível à população nãoproprietária de áreas de pastagem, mediante a tomada de posse de terras devolutas. Pedregosos, de solo arenoso e vegetados pela variada - e frágil - flora de campos rupestres e de altitude, estes terrenos vão aos poucos se empobrecendo, abrigando pastos ralos de braquiárias. A capitalização obtida pelo turismo não tem sido aplicada na estruturação dos meios de serviço e sim, no mais das vezes, na compra de reses, arame farpado e mourões estes dois últimos itens destinados também ao posseamento, com vistas a um aquecido e especulativo mercado imobiliário.

Os picos sazonais de turismo e veraneio comprometem a qualidade de vida $-\mathrm{e}$ a sustentabilidade da atividade turística - e a fraca mobilização observável na comunidade tem se revelado incapaz de lidar com questões como o tráfego e estacionamento de veículos, o uso de balneários e áreas de preservação, o abastecimento de água, a coleta e destinação do lixo e a segurança pública. Há que assinalar que estes problemas constituem um processo, e não um quadro estático, e pôde ser observada ao longo dos anos uma incipiente conscientização e mobilização da comunidade, impondo restrições ao turista. Assim, hoje em dia não é mais possível acampar em locais públicos. Por outro lado, os milhares de visitantes - que chegam a quadruplicar ou quintuplicar a população de Milho Verde (aos aproximadamente 600 residentes fixos na área urbana somam-se, às vezes, mais de 2.000 pessoas durante os feriados) - representam uma multidão de difícil manejo mesmo para uma coletividade muito mais estruturada, e diversos problemas encontram-se ainda por resolver.

\section{Um Turismo Planificado}

A distribuição da renda advinda do turismo, aponta Jost Krippendorf (2001), é menor em regiões de menor desenvolvimento econômico. Embora os empreendimentos turísticos obtenham a renda principalmente de visitantes egressos das grandes cidades e das áreas de maior produtividade, é para estas mesmas regiões que os recursos financeiros retornam, quase invariavelmente. Isto ocorre porque, tal como apontado no estudo realizado por Fonteles em Jericoacoara, Ceará (2004), embora a população das comunidades de destino disponha inicialmente da posse do solo e represente ela própria a força de trabalho, estes itens terminam sendo adquiridos a preços módicos. Nas palavras de Krippendorf: “[...] muitas regiões 
turísticas liquidam seus recursos, sem se dar conta de que estão perdendo, cada vez mais, a própria independência. Elas se desfazem da vaca, em vez de vender o leite” (2001).

Krippendorf salienta ainda que, em nome das exigências de pessoal qualificado, atendimento aos gostos e preferências da clientela e da necessidade de um alto padrão nas estruturas de serviços, os empreendedores externos muitas vezes contratam profissionais e fornecedores de fora da comunidade, e isso reforça a tendência de evasão dos recursos, ao passo que os custos sociais e ecológicos serão pagos, inexoravelmente, pelos "autóctones", como o autor os designa. Pôde ser observado que, de lugar "visitado", Milho Verde tem passado, gradativamente, à condição de "servidora" do turismo. O comentário do empreendedor de turismo mencionado a seguir denota uma série de modificações que estão a ocorrer na demanda do turismo em Milho Verde:

Porque o turista que antigamente vinha aqui ficou apaixonado com a receptividade do lugar. [...] era um turismo mais romântico. Pessoas que gostavam da receptividade familiar, em casa. Que gostavam da simplicidade, que gostavam de desconectar da cidade e entrar aqui numa casa, ser recebido, sentar na cozinha... [...] Essa qualidade de turismo não está mais sendo procurada. Porque as pessoas na cidade nem conhecem isso, nem mesmo sabem procurar isso.

Tofani (2004) assinala que, embora o turismo tenha possibilitado que estruturas sociais fechadas, patriarcais e de baixo nível de escolaridade formal ao redor de todo o mundo desenvolvam um perfil mais cosmopolita, o saldo geral parece ser negativo, pois deixam-se graves seqüelas na natureza e dissolve-se a diversidade cultural. Homogeneizadas, as comunidades transformam-se em lugares impessoais e artificiais. $\mathrm{O}$ autor adverte ainda quanto à degradação e comoditização dos destinos que, tal como no ciclo de vida mercadológico de qualquer outro tipo de produto ou serviço, tendem a perder competitividade face às dinâmicas da concorrência e às transformações dos hábitos de consumo e das bases tecnológicas. Esse processo parece poder ser averiguado a partir de vários comentários de empreendedores locais, como o seguinte:

[...] acho que a gente já está no pós-turismo, aqui. O auge do turismo, nativo, natural, vamos dizer assim, espontâneo, em Milho Verde foi nos anos 90. Agora, com o turismo planejado, o lugar ainda não deu conta. E deu uma caída boa no movimento aqui. Porque as pessoas não são, acho que não são codificadas. A linguagem do novo momento turístico não se encaixou aqui. 
Pertencentes a esse quadro de um "novo momento turístico" figuram projetos de desenvolvimento que visam integrar regiões inteiras ao mercado global de turismo, representados na região pela iniciativa do Programa de Desenvolvimento da Estrada Real e também pelo Prodetur Nordeste II. De um modo geral, embora grande parte dos preparativos e resultados locais visados por estas duas atividades de fomento não se tenha configurado ainda, pôde-se observar que os impactos ora determinados, ou a serem determinados pelo desenvolvimento do turismo não estão sendo mediados - ou sequer compreendidos - pela população local. Não existe entre a comunidade a noção do papel que se deva exercer em uma atividade de turismo integrada a roteiros abrangentes ou em uma estrutura de serviços de turismo que inclua divulgação, captação de clientes e atendimento a expectativas criadas na demanda. O próprio conceito de roteiro turístico, em si, não pôde ser observado ao longo das entrevistas e observações como sendo uma referência compreendida pela comunidade considerando-se ainda que, de um modo geral, a própria atratividade turística local é pouco percebida e compreendida. O comentário a seguir, de uma empreendedora de turismo nascida na região, resume o que foi manifesto por vários entrevistados:

Eu gostaria de, aqui na nossa comunidade, ter um encontro falando sobre essa Estrada Real. Pelo menos eu não sei muito, e não é pra aprofundar, não, mas pelo menos para saber o que é isto... o que significa Estrada Real.

O macro-empreendimento denominado e divulgado como Estrada Real, orientado à promoção de desenvolvimento econômico e social através do fomento à atividade turística, tem um marco de efetivação no ano de 1999, data de início das atividades do Instituto Estrada Real IER (integrante da Federação das Indústrias do Estado de Minas Gerais - Sistema Fiemg). A entidade promove a divulgação e a cooperação da grande região associada ao ciclo minerador colonial em um roteiro de atrações históricas, culturais e ecológicas, utilizando como conceito integrador o percurso físico provido pelos antigos itinerários controlados pela Coroa portuguesa para o acesso às lavras de minerais preciosos - a assim denominada Estrada Real.

O complexo de itinerários abrangido pelo roteiro distribui-se ao longo dos cerca de 1.400 quilômetros percorridos por três trajetos principais (de Paraty a Ouro Preto, do Rio de Janeiro a Ouro Preto, e de Ouro Preto a Diamantina) e cobre uma vasta região que engloba 177 municípios, destes 162 em Minas Gerais, oito no Rio de Janeiro e sete em São Paulo. Designado como um dos projetos estruturadores do atual programa de governo do Estado de 
Minas Gerais, o Programa de Desenvolvimento da Estrada Real constitui, em seu escopo abrangente, uma iniciativa coordenada entre iniciativa privada, orgãos públicos e sociedade civil com vistas ao desenvolvimento econômico e social das regiões abarcadas pelo roteiro, e vem sendo apoiado pelos governos municipais implicados, pelas instâncias govenamentais estaduais do Rio de Janeiro e de São Paulo, pelo governo federal e por diversas entidades públicas e privadas, entre elas o Sebrae e o Banco Interamericano de Desenvolvimento - BID. A divulgação já rodou o mundo e tem encontrado ampla repercussão na mídia nacional. Uma das metas visadas pelo Programa é atingir, somando-se as visitações experimentadas nos diversos destinos turísticos distribuídos ao longo dos trajetos, um fluxo anual de 2,5 milhões de visitantes até o final de 2007 (Anuário Exame, 2007).

O Programa de Desenvolvimento do Turismo no Nordeste - Prodetur NE consiste, basicamente, em um programa de crédito destinado a prover recursos para Estados, municípios e empreendedores, com vistas à melhoria e expansão da atividade turística e, simultaneamente, à melhoria da qualidade de vida das populações residentes nas áreas beneficiadas. A maior parte dos recursos alocados pelo Prodetur NE provêm do BID e são designados com base em levantamentos sobre as realidades econômicas e sociais dos municípios a serem abordados. O Programa encontra-se atualmente em uma segunda edição, o Prodetur NE II, que abrange estados do Nordeste e também do Norte do país, o Espírito Santo e o Norte e o Nordeste de Minas Gerais. ${ }^{9}$ Além de financiamento aos empreendedores e implementação de infra-estrutura - saneamento, sistema viário e urbanização -, o Programa destina recursos à proteção do patrimônio natural, histórico e cultural e à capacitação profissional. Destacadamente, o Prodetur NE II previu, entre demais reformas nos acessos viários da região, a verba necessária às obras de asfaltamento e calçamento do trecho de estrada até Diamantina, que o tornará mais transitável, sendo os intervalos de calçamento menos impactantes que o asfalto às condições urbanas, ao caráter histórico e aos atrativos naturais das regiões que atravessam. Milho Verde, antes visitada apenas intencionalmente, devido às más condições do trajeto, voltará a ser uma escala ao longo de uma estrada.

Para promover uma maior estruturação dos empreendimentos locais com vistas ao atendimento das novas demandas de serviços associadas ao turismo (hospedagem, entretenimento, alimentação, conservação patrimonial e ambiental, administração), estão

\footnotetext{
${ }^{9}$ As implicações econômicas, sociais e ecológicas de empreendimentos conduzidos na primeira fase do Prodetur foram reportadas e avaliadas. Alguns artigos acadêmicos que abordam este tema específico podem ser encontrados na coletânea organizada por Amália Lemos - Turismo: impactos socioambientais (2001).
} 
sendo oferecidos atualmente pelo Sebrae, pelo Senac e pelo Fundo de Amparo ao Trabalhador - FAT cursos diversos de capacitação, disponibilizando-se formações profissionalizantes básicas em administração hoteleira, organização de eventos, culinária, serviços de guias turísticos, entre outros, freqüentados com interesse pelos habitantes de Milho Verde e de localidades vizinhas.

\title{
5. A Precária Globalização da Aldeia
}

Sabedora das condições de atendimento caseiro praticadas em seu próprio estabelecimento e também em todo o restante da comunidade, e ciente do contraste entre estas condições e as expectativas atuais do público, um dos empreendedores entrevistados estabeleceu a seguinte precaução:

A pessoa que vem pra cá, os que ligam pra mim, eu dou essa informação — "Nós moramos numa vila. Simples."

O entrevistado prossegue, estabelecendo um prognóstico em que as condições de baixa estruturação dos serviços oferecidos pela comunidade, defrontadas com a crescente exigência da demanda, tendem a configurar um futuro de baixa competitividade para o negócio local:

\begin{abstract}
$\mathrm{Ah}$, mas eles têm que entender que eles não vão procurar o que encontram em Diamantina e vão encontrar aqui. E não são todos que entendem. [...] porque já é um jeito da gente aqui em Milho Verde. Aqui pode entrar, minha casa é simples, é desse jeito aí. Outros já exigem certos confortos que não tem condições da gente oferecer pra eles aqui. Então vai chegar o ponto em que a gente pobre [...] vai ter que ficar... só em família da gente mesmo.
\end{abstract}

Prevalecente na totalidade ou quase totalidade das organizações e atividades produtivas locais e relacionada às macro-condições de organização sócio-econômica do país, a informalidade do trabalho constitui também um traço cultural decorrente - talvez, nas regiões anteriormente inseridas no Distrito Diamantino, mais do que alhures - das condições econômicas e sociopolíticas da mineração colonial. Nesse contexto, cabe questionar como as organizações e os trabalhadores se percebem, ou se posicionam, com relação ao ambiente comunitário e ao macro-ambiente político. A condição informal de trabalho significa postular-se, ou aceitar-se, uma condição de marginalidade, a continuidade de um posicionamento de informalidade instilado na cultura local? O trecho de entrevista transcrito a seguir deixa entrever - de forma 
correspondente à mentalidade local observada -, a prevalecente subordinação do empreendimento e do trabalho a uma configuração política e econômica situada alhures, além do alcance de intervenção da comunidade:

Esse trem aí vem lá de cima [Estrada Real], vou falar que é de Brasília, por exemplo, porque eu nem sei de onde é que sai.

Uma avaliação das implicações sociopolíticas da economia turística em Milho Verde pode ser referenciada em Colin Hall (1998), que analisa as conjunturas políticas presentes na organização do turismo em diversas dimensões de coletividade, desde a escala global, passando pelo planejamento turístico estatal realizado em esferas nacionais ou regionais, chegando até o nível dos interesses comunitários de pequenas localidades. Com relação à mobilização comunitária, o autor correlaciona um maior envolvimento comunitário e um conseqüente maior controle sobre mudanças sociais e econômicas originadas da inclusão de pequenas comunidades na economia do turismo. O conceito de controle utilizado pelo autor relaciona-se a itens como a manutenção da propriedade da terra pelos habitantes locais, a obtenção de crédito, a manutenção ou obtenção de possibilidades comerciais que possam sustentar um auto-financiamento, a capacidade de exercício de pressão em prol da absorção dos habitantes locais nos empreendimentos turísticos implementados por investidores externos e o grau de relação mantido entre tradições e instituições locais e os escopos de planejamento e implementação de projetos de desenvolvimento do turismo. ${ }^{10}$

Hall assinala que o grande obstáculo à obtenção de um maior grau de controle comunitário local sobre o planejamento e a tomada de decisão em projetos de desenvolvimento pelo turismo reside em que os responsáveis pelo planejamento não adotam, em geral, uma abordagem comunitária: "comunidades raramente têm oportunidade de dizer não" (1998 tradução livre). A ausência do cidadão comum em fóruns de decisão tornaria a concepção de projetos de desenvolvimento pelo turismo um espaço que privilegia as relações entre poderes públicos e interesses privados.

Dada a crescente relevância dos impactos determinados pela atividade turística em Milho Verde, constituindo uma grave ameaça à sustentabilidade econômica e ambiental, constata-se, da observada passividade coletiva, que a população local não desenvolveu uma noção de

${ }^{10}$ As conclusões de um estudo conduzido por Calvente em Ilhabela, São Paulo, podem ser mencionadas como indicativas da correlação traçada por Hall entre a coesão comunitária e o controle sobre mudanças provocadas pela atividade turística (Hall, 1998; Calvente, 2001). 
identidade comunitária suficientemente consolidada para lidar adequadamente com as solicitações - oportunidades e ameaças - que experimenta. Vinculados em níveis primordiais de clãs, os cidadãos de Milho Verde não compõem articulações que possam sustentar posições comunitárias frente a oposições internas ou externas, ou sustentar reivindicações coletivas, atuando como grupo de pressão nos âmbitos políticos de que participam, sequer no mais imediato, o municipal. Na atual condição sociopolítica comunitária, orfã do poder senhorial destituído, as relações políticas locais tendem a ser compreendidas como relações de mando, de autoridade de um senhor sobre servos, fundadas no estereótipo praticamente único disponível nas referências da formação da comunidade.

Entretanto, pequenas mobilizações esporádicas apontam um potencial de maior coesão e politização comunitária. São empreendidas, de forma voluntária, algumas atividades esparsas de manutenção das instalações públicas - limpeza urbana, limpeza de reservatórios de água, restrições no sistema viário. Não havendo institucionalidade que coordene a mobilização, a captação e a utilização de recursos, o empreendimento destas atividades baseia-se em lideranças informais e em um senso de obrigação com relação a determinados valores comunitários. E, mesmo desarticulada, a comunidade parece estar exercendo influência gradual na atração de um perfil mais desejável de turista. O empreendedor mencionado a seguir caracteriza o interesse da comunidade na restrição do comportamento do turista, não somente pelo prisma de valores associados à conduta, mas também pelo interesse na economia do turismo:

Há dez anos atrás, turista era rei, podia fazer o que queria, porque estava trazendo dinheiro. Agora, a cidade mesmo está impondo regras para o turista. Há dez anos atrás, você podia acampar no Rosário, acender fogueira na grama, estava tudo certo. Agora já estão visando outro tipo de turismo, mais familiar, mais calmo.

Porém, o quadro geral atual parece mesmo reconfigurar condições arcaicas: os empreendimentos em turismo são compreendidos como meramente extrativistas: dispõem de recursos (os "atrativos") da natureza em estado bruto, não processados e tratados como nãoconserváveis - não-sustentáveis; comprometem-se unicamente com uma consecução imediatista, à mercê de demandas e diretrizes externas; e não se buscam aprimoramentos na 
organização local, sejam técnicos ou políticos, com vistas à consolidação de condições que garantam a continuidade da exploração no futuro. ${ }^{11}$

\section{Da Subsistência à Sustentabilidade?}

Variadas propostas que incorporam conceitos de desenvolvimento sustentável podem ser observadas hoje em modalidades turística oferecidas ao mercado que integram as dimensões social, cultural e ambiental, com vistas à minimização ou eliminação dos impactos e à possibilidade da manutenção do desenvolvimento no longo prazo (Mendonça, 2001; Rodrigues, 2003; Ruschmann, 2002; Swarbrooke, 2000). Carminda Cavaco contrapõe a visão convencional, planificada, de desenvolvimento pelo turismo a uma abordagem de desenvolvimento local que atenda aos seguintes requisitos:

[...] endógeno (mobilização dos próprios recursos), ascendente (protagonismo dos agentes locais), autocentrado (centrado nas necessidades próprias das comunidades) e sustentável [...] cujo sentido está parcialmente incluído no de desenvolvimento local, ou desenvolvimento alternativo (1996).

A idéia geral de desenvolvimento alternativo apresenta-se em uma corrente de ações e estudos de certo modo oposta às premissas de formulação e implementação de projetos de desenvolvimento por parte de agências tecnocráticas nacionais e internacionais, tradicionalmente centradas em aceleração do crescimento econômico, notadamente por meio de estímulos ao setor industrial. A ênfase macroeconômica das propostas de aceleração do crescimento vincula-se, em grande medida, à tentativa de manutenção de condições propícias a regimes de acumulação capitalistas alternativos ao hoje esfacelado modelo fordista, prevalecente, segundo alguns autores, até os anos setenta (Boyer, 1992), e estaria associada à marginalização de outros objetivos econômicos, sociais e políticos, tais como a distribuição

\footnotetext{
${ }^{11}$ De modo geral, a comunidade de Milho Verde, bem como a instância municipal serrana (de parcos recursos e desconectada da vocação turística do distrito), não realizam benfeitorias ou organização nos espaços públicos com vistas à operacionalização de atrativos turísticos disponíveis, à qualificação do atendimento, à regulação dos influxos de demanda e à salvaguarda da qualidade de vida da população. Mesmo no Plano Diretor municipal, recém-elaborado, não se prevêem medidas para a institucionalização e manutenção de atrativos históricos. Ainda nesta linha, as incipientes tentativas de restrição de acesso e de manejo sustentado de áreas de preservação e atrativos naturais esbarram em obstáculos relativos a necessidades de subsistência dos habitantes e na inefetividade da implementação de decisões coletivas face ao comportamento individualizado predatório, tanto do habitante local como do turista.
} 
equilibrada, eqüânime e ecologicamente responsável dos frutos deste desenvolvimento (Santos e Rodríguez, 2005).

O comentário a seguir, de um empreendedor de turismo local, questiona os pressupostos de atuação das iniciativas de fomento à atividade turística que ora abordam a região:

[...] Qual é o "ouro" do Vale do Jequitinhonha? Cultura. [O] saber primitivo, esse é o ouro da região. E quem vai viver dele? Pelo discurso da sustentabilidade, deveria ser o povo do lugar. Mas, pela planificação do turismo, que estabelece um nível de consumo, utiliza-se essa cultura que foi mantida guardada - que, na verdade, só existe porque o Vale do Jequitinhonha nunca foi objeto de nenhum projeto de desenvolvimento.

E parece mesmo possível ponderar que, vinculando-se a economia local a premissas globais de competitividade, eficiência e consumo, dadas as condições formacionais e as possibilidades econômicas locais, conformar-se-á, a priori, uma "insustentabilidade". Vinculada a agências de turismo e roteiros turísticos que estipulam demandas formatadas em expectativas padronizadas de consumidores globais, a serem atendidas por recursos tecnológicos, financeiros, logísticos e de administração oriundos de uma realidade externa, bastante diversa e muito mais desenvolvida, a população local encontrar-se-á descompassada em relação à nova atividade que vem sendo promovida.

Em geral, as entidades de fomento da atividade turística e do empreendedorismo demonstram-se conscientes da problemática do descompasso local em relação ao conteúdo geral, e geograficamente abrangente, das propostas de desenvolvimento. Um entrevistado, pertencente a uma destas entidades, menciona o que pode ser talvez um dos aspectos mais polêmicos da dinâmica de desenvolvimento pelo turismo, da forma como tem sido experimentada em cidades históricas de Minas Gerais:

[...] se você não desenvolver o capital humano, você cria destinos não sustentáveis, onde os bens foram desenvolvidos e os empresários de fora chegam e se apossam daquela matéria-prima, que é belíssima: Ouro Preto, Tiradentes, Diamantina. O empresário chega com uma visão mais elaborada, capitalista e simplesmente se apossa da matéria-prima que... não tem dono. Não é dizer que é só de quem mora lá, porque não há uma fronteira. $\mathrm{O}$ mundo é de todo mundo. 
Alguns dos empreendedores locais questionam que essa dinâmica excludente não tem sido evitada na própria concepção das iniciativas encetadas:

Essas garantias que eles [orgãos financiadores] pedem são para grandes empreendedores, não para pequenos, para comunidades como essa daqui, em que as pessoas não têm a escritura de nada, porque isso tudo era terra devoluta, que foi sendo cercada e construída. Então, quando se acenou com a possibilidade de uma linha de crédito, ou coisa assim, ela não é para a gente. É para quem? Para grandes empresários, pra quem tem.

Uma definição para as questões controversas relacionadas às propostas de desenvolvimento pelo turismo que ora abordam Milho Verde e região pode ser disposta nos termos de uma dissonância, decorrente da instrumentalização de todo um universo de "recursos" relacionados à atratividade turística e à prestação de serviços de turismo - incluindo-se aí a natureza, as comunidades e os patrimônios culturais, históricos, urbanísticos e arquitetônicos. Essa orientação finalística condiciona as ações de desenvolvimento encetadas, primordialmente, à rentabilidade dos investimentos empregados (Carrieri, 2000; Fonteles, 2004), subordinando assim os contextos e dinâmicas locais a ações e objetivos que não provêm, em última análise, dos objetivos, valores ou necessidades próprias às comunidades, indivíduos, ecossistemas, culturas e tradições implicados. Calcadas em um estímulo a uma maior demanda, a ser atendida por uma infra-estrutura melhorada e uma mais capacitada estrutura de serviços, ambas alavancadas por investimentos volumosos, as propostas de desenvolvimento estabelecem um “jogo de grandes”, dissonante não apenas com relação aos interesses de parcelas das populações implicadas, mas com toda a coerência de uma noção de desenvolvimento local.

Nesse contexto, podem ser questionadas algumas das atividades de qualificação de empreendedores e trabalhadores em Milho Verde, oferecidas no âmbito dos projetos de desenvolvimento e que, embora visem compensar as deficiências ou defasagens locais, parecem estar entretanto justamente ignorando estas deficiências. Figuram como exemplos os cursos destinados à qualificação de meios de alimentação. O comentário transcrito a seguir assinala a dissonância entre as práticas postuladas e os recursos do empreendedor local:

Te falam que tem de ter o abatedor de calor na cozinha, é claro, teria de ter. Mas um equipamento que custa dez mil reais, quem vai comprar? Te falam: "Na cozinha, você tem de ter uma mesa para picar carne, uma mesa para picar verdura, 
uma pia pra lavar as verduras, uma pia pra lavar louça, uma pia pra lavar as panelas.” Aqui, graças a Deus, tem uma pia pra lavar. Em uma só, na cozinha, você faz tudo. Tem que adaptar o curso pra realidade, não adaptar a realidade pro curso.

Dadas as condições locais observadas, pode-se afirmar que a rentabilidade do trabalho para a população, seja como empreendedores autônomos, seja como trabalhadores em posições melhor qualificadas e remuneradas, dependerá da elaboração de condições sociais para o trabalho. $^{12}$

No que concerne a uma preocupação mais ampla, relativa à manutenção da sustentabilidade do turismo local, deve ser considerado ainda que os empreendimentos informais em Milho Verde encontram-se desvinculados de aspectos de mobilização comunitária capazes de resguardar a qualidade de vida e a atratividade turística locais. Lançando mão dos recursos que lhe são disponíveis para aumentar o volume de negócios e a rentabilidade, o habitante local tem colocado em risco atrativos urbanos e o ecossistema local; além disso, o esvaziamento dos valores humanos, culturais e comunitários repercute negativamente na possibilidade de reprodução da atividade turística - pelo menos, de uma atividade que privilegie a população local.

Nesse sentido, deve ser indicado que a efetividade de um desenvolvimento pelo turismo, contemplando-se a realidade social local, tem sido enfatizada no âmbito de uma iniciativa específica, ora encetada. $\mathrm{O}$ entrevistado citado a seguir, atuante em uma entidade de fomento ao empreendedorismo, faz menção a uma formulação alternativa de atividade turística (e de desenvolvimento pelo turismo) geralmente designada como "turismo social" (Krippendorf, 2001; Goeldner, Ritchie e McIntosh, 2002) e que se caracteriza, em essência, por uma adequação da demanda às condições do local visitado, e não o contrário:

Existe um turista hoje no mundo que busca conhecer o que acontece, sem maquiagem, com as localidades [...] como é a dinâmica social [...] Então, a gente começou a trabalhar com essas localidades do Serro: Milho Verde, Capivari e São

\footnotetext{
${ }^{12}$ Uma tendência à elitização do trabalho tende a ocorrer em meio à implícita promoção da competição da população local com investidores-empreendedores externos. Outro fator excludente é que a demanda ora estimulada, com vistas à necessária rentabilidade dos capitais financiador e investidor implicados, se destina a serviços de maior valor agregado, requerendo assim um nível de qualificação não disponível entre a mão-de-obra local. A baixa qualificação de trabalhadores locais tende a ser vista, inclusive, nos âmbitos empresariais de turismo, como um obstáculo à rentabilidade dos empreendimentos, e não sob o prisma de implicações que afetem a sustentabilidade. Sob a lógica predominante nos empreendimentos de turismo, as comunidades locais compõem, basicamente, um recurso a ser empregado: uma fonte abundante e barata de mão-de-obra - porém mais ou menos qualificada conforme sinalize o IDH municipal (cf. Anuário Exame, 2007).
} 
Gonçalo do Rio das Pedras. [...] Preparar a [...] própria casa deles, sem ter que sair de casa pra receber os turistas.

A denominação Turismo Solidário provê uma dupla conotação de economia solidária (cooperativa), no âmbito das comunidades abordadas, e de solidariedade, no que se refere à atitude do visitante. A cooperação entre membros é vista, nos termos da proposta, como uma ferramenta para a constituição de serviços ao turista (meios de hospedagem, alimentação e entretenimento) de maior capacidade e mais diversificados, sem que, para isso, se demandem meios outros que não os da própria mão-de-obra e da estrutura domiciliar e urbana locais. Experimentando níveis variados de receptividade e efetividade nas diferentes comunidades que aborda, a aplicabilidade dessa proposta tem sido avaliada como muito abrangente pois, dentro das condições sócio-econômicas a que se destina, podem ser encontradas pléiades de pequenas localidades brasileiras em que o potencial turístico acompanha-se de um baixo desenvolvimento.

A comunidade de Milho Verde tem se mostrado receptiva à proposta do Turismo Solidário; uma penetração maior talvez não tenha sido atingida em função de que o recurso principal demandado para efetivação do programa é algo que, como foi demonstrado anteriormente, constitui mesmo uma carência local: mobilização comunitária. Um outro senão a considerarse em relação à aplicabilidade local do Turismo Solidário deriva da já caracterizada e cada vez mais acentuada exposição de Milho Verde a um ambiente competitivo de atividade turística. $^{13}$

\footnotetext{
${ }^{13}$ Tendo-se em mente uma discussão acerca da efetividade das atividades de desenvolvimento pelo turismo ora entabuladas, alguns aspectos específicos relativos à aplicabilidade local do Turismo Solidário precisam ser observados. Dado que Milho Verde insere-se na economia do turismo há mais de três décadas, possuindo considerável atratividade turística e estando situada em uma rota que receberá em breve melhorias de acesso viário ao centro metropolitanod de Belo Horizonte, observe-se que a comunidade como um todo encontra-se exposta a um ambiente competitivo de negócios de turismo. Assim, programas de turismo social tenderão a secundar, ou contrapesar, uma macro-dinâmica turística que permanecerá impactando crescentemente a localidade, nos termos de uma competição capitalista. Uma formulação de turismo social parece ser especialmente válida quando em referência a uma comunidade desconectada de outros contextos e modalidades turísticas. Parte da visitação verificada em Milho Verde nas três últimas décadas enquadra-se na caracterização de um turismo social, mas esse tipo de visitação, a ser realizada em maior sintonia com as condições sócioeconômicas locais, segundo a opinião mesma de vários dos entrevistados, já não corresponde ao quadro geral observável da atividade turística atual. O que se verifica hoje é um menor envolvimento dos visitantes com a realidade local, e a necessidade de adequação dos serviços prestados a exigências de maior valor agregado, manifestadas por parcelas cada vez mais significativas da demanda.
} 


\section{Conclusão}

Milho Verde insere-se hoje em um conjunto de solicitações mercadológicas e culturais referenciadas além de etapas de modernização não atingidas no decurso da evolução social local. A autodeterminação individual e coletiva, a reivindicação de direitos civis e a democratização e participação, necessárias à interação com as instâncias que afetam o modo de vida da comunidade, não se constituíram ali. Entretanto, a proposição de emprendedorismo para o habitante local é paradigmática nas iniciativas de desenvolvimento do turismo, propugnadas em um ambiente político em que a livre iniciativa, o livre mercado e a responsabilização da sociedade civil constituem credos fundamentais.

As propostas planificadas têm custodiado prerrogativas de desenvolvimento, tais como a implementação acelerada de infra-estruturas. Prefigura-se, porém, que o simples desencadeamento do quadro amplo de fomento à demanda e de implementação de infraestruturas demonstre-se, em alguns de seus efeitos, potencialmente desagregador e excludente. A questão sobrepassa uma discussão acerca da distribuição dos benefícios econômicos do desenvolvimento, pois remete à própria integridade do processo de fomento à atividade: frente às condições regionais de fragilidade econômica e social, reforça-se a necessidade de integração comunitária à consecução das iniciativas, como condição sine qua non para a sustentabilidade da atividade turística e para que uma proposta de desenvolvimento efetivamente atinja as necessidades das populações locais.

Pimenta e Corrêa (2001) assinalam que as condições históricas de tutela do Estado sobre a cidadania contribuíram para que não se compusessem na sociedade brasileira as noções de igualdade e de legitimidade do conflito, mas sim uma naturalização da hierarquia e das diferenças de direitos. Nesse contexto, é através da organização e da contestação que se remodelam estes significados de dominação e exclusão e que se opõem reivindicações de igualdade às condições estruturais de conflito. A partir desta tomada de consciência, "o processo de gestão se torna uma arte", cabendo compreenderem-se e abrangerem-se as dimensões culturais e simbólicas da gestão de organizações, em seu papel de construção de novos espaços de legitimidade (2001). Em meio à precariedade dos empreendedores locais, desprovidos de capitalização e escolaridade, e à fragilidade do ecossistema do entorno face aos impactos crescentes - na maior parte provocados pela própria comunidade -, a compreensão de um papel social ampliado para os empreendedores torna-se mesmo mais importante do que quaisquer das capacitações técnicas providas pelas entidades que atuam no fomento e na qualificação dos serviços de turismo. 
As incipientes manifestações de autonomia observadas em Milho Verde não devem, portanto, eventualmente ser consideradas sob o prisma de uma "insuficiência", mas como fatores primordiais de um desenvolvimento possível e necessário, por mais defasado que se encontre de uma proposta contextualizada. Uma amostra do potencial para este desenvolvimento pode ser indicada nas modificações observadas, em anos recentes, no trato da comunidade com o turista.

Uma "cidade-mina", cidade-exploração, tende a ser o oposto de uma cidade-preservação, cidadesustentável - necessária ao turismo. E é nesse sentido que uma preocupação local com as condições mais estritas de sustentabilidade fazem-se necessárias, e também nesse sentido a idéia do turismo apresenta o potencial positivo de um contraste com a mentalidade de uma população para quem - consideradas as condições específicas, em um passado até mesmo recente "sustentabilidade" poderia ser definida justamente como a provisoriedade, a informalidade, a inacessibilidade e o segredo. Estes não cidadãos, desprotegidos por quaisquer outras instâncias, poderão sucumbir perante as forças do mercado, não somente como competidores ultrapassados, ou relegados à condição de (sub)mão-de-obra, mas pela própria perda da sustentabilidade turística. Sem atenção às circunstâncias e ritmo locais, ao invés de promover desenvolvimento, o estímulo à demanda e os cuidados com a infra-estrutura irão, de fato, ameaçar a comunidade de Milho Verde, ocasionando ainda maiores problemas ecológicos e urbanos, comprometimento da atratividade turística e exclusão social.

\section{Referências}

ANUÁRIO EXAME. 2007. Turismo 2007-2008. São Paulo: Abril.

ARNDT, Jorge Renato Lacerda. 2007. Entre tradição e modernidade: sustentabilidade do desenvolvimento pelo turismo em uma comunidade tradicional de Minas Gerais - Estudo de caso em Milho Verde, Alto Jequitinhonha. Dissertação de mestrado em Administração. Belo Horizonte: FEAD. Disponível em http://www.fead.br.

BOYER, Robert. 1992. Alternativas ao fordismo: uma análise provisória. In: Revista Crítica de Ciências Sociais, n. 35, [s. 1.].

CARRIERI, Alexandre de Pádua. 2000. Organizações e meio ambiente: mudança cultural. In: RODRIGUES, Suzana Braga; CUNHA, Miguel Pina (orgs.). Novas perspectivas na administração de empresas. São Paulo: Iglu.

CAVACO, Carminda. 1996. Turismo rural e desenvolvimento local. In: RODRIGUES, Adyr Balastreri. (org.). Turismo e geografia: reflexões teóricas e enfoques regionais. São Paulo, Hucitec.

FONTELES, José Osmar. 2004. Turismo e impactos socioambientais. São Paulo: Aleph.

FURTADO, Júnia. 1996. O Livro da Capa Verde: o Regimento Diamantino de 1771 e a vida no Distrito Diamantino no período da Real Extração. São Paulo: Annablume. 
GALIZONI, Flávia Maria. 2000. Migrações, família e terra no Alto Jequitinhonha, Minas Gerais. In: Anais do IX Seminário sobre a Economia Mineira. Diamantina: CEDEPLAR/UFMG. Disponível em http://www.cedeplar.ufmg.br/diamantina2000/textos/FLAVIA.PDF. Acesso em 14/02/07 10:23.

GOELDNER, Charles R; RITCHIE, J. R. Brent; MCINTOSH, Robert. W. 2002. Turismo: princípios, práticas e filosofias [2000], 8 ed. Porto Alegre: Bookmann.

HALL, Colin. Michael. 1998. Tourism and politics: policy, power and place [1994]. Chichester (England): Wiley.

KRIPPENDORF, Jost. 2001. Sociologia do turismo [1985], 2ed. São Paulo, Aleph.

LUNA, Francisco Vidal. 1980. Minas Gerais: escravos e senhores. Análise da estrutura populacional e econômica de alguns núcleos mineratórios (1718-1804). Tese de doutorado em Economia. São Paulo: USP. Disponível em http://www.brnuede.com/pesquisadores/paco/pdf-paco/li2.pdf. Acesso em 11/09/2006.

MARTINS, Marcos Lobato. 2000. A presença da fábrica no "Grande Empório do Norte": surto industrial em Diamantina entre 1870 e 1930. In: Anais do IX Seminário sobre a Economia Mineira. Diamantina: CEDEPLAR/UFMG. $\quad$ Disponível em http://www.cedeplar.ufmg.br/diamantina2000/2000/MARTINS.pdf. Acesso em 14/02/07.

MATA MACHADO FILHO, Aires da. 1980. Arraial do Tijuco, cidade Diamantina, 3 ed. São Paulo: Itatiaia/EDUSP.

1985. O negro e o garimpo em Minas Gerais [1938]. São Paulo: Itatiaia/EDUSP.

MATOS, Ralfo. 2000. Populações do Vale do Jequitinhonha e movimentos migratórios. In: Anais do IX Seminário sobre a Economia Mineira. Diamantina: CEDEPLAR/UFMG. Disponível em http://www.cedeplar.ufmg.br/diamantina2000/textos/RALFO.PDF. Acesso em 14/02/07.

1990. O distrito de Milho Verde: formação, configuração e alternativas de desenvolvimento. In: Geografia e ensino, n. 10 p. 37-43. Belo Horizonte: IGC/UFMG.

MAWE, John. 1978. Viagem ao interior do Brasil [1812]. São Paulo: Itatiaia/EDUSP.

MENDONÇA, Rita. 2001. Turismo ou meio-ambiente: uma falsa oposição? In: LEMOS, Amália Inês Geraiges de Lemos. (org.). Turismo: impactos socioambientais. 3 ed. São Paulo: Hucitec.

PIMENTA, Solange Maria; CORREAA, Maria Laetitia. 2001. Novos olhares sobre gestão, trabalho e cidadania: as possibilidades de outras articulações -Apresentação, p. 9-18. In: PIMENTA, Solange Maria; CORRÊA, Maria Laetitia (orgs.). Gestão, Trabalho e Cidadania - novas articulações. Belo Horizonte: Autêntica/CEPEAD/FACE/UFMG.

PIVA, Adriana et al. 2007. Os cantos sagrados de Milho Verde. Catálogo de divulgação do projeto Tradição dos Cantos Sagrados de Milho Verde. Milho Verde: edição dos autores.

RODRIGUES, Adyr Balastreri. 2003. Ecoturismo: limites do eco e da ética. In: RODRIGUES, Adyr Balastreri (org.). Ecoturismo no Brasil: possibilidades e limites. São Paulo: Contexto.

RUSCHMANN, Doris. 2002. Turismo no Brasil: análise e tendências. São Paulo: Manole.

SAINT-HILAIRE, Auguste de. 1974. Viagem pelo Distrito dos Diamantes e pelo litoral do Brasil [1830]. São Paulo: Itatiaia/EDUSP.

SANTIAGO, Luís. 2006. Serro: política, geografia e cultura. In: O vale dos boqueirões: história do Vale do Jequitinhonha, v. 3. Belo Horizonte: Morada Santiago.

SANTOS, Joaquim Felício dos. 1976. Memórias do Distrito Diamantino da Comarca do Serro Frio [1864]. 4 ed. São Paulo: Itatiaia/EDUSP.

SANTOS, Boaventura de Sousa; RODRÍGUEZ, César. 2005. Introdução: para ampliar o cânone da produção. In: SANTOS, Boaventura de Sousa. (org.). Reinventar a emancipação social para novos 
manifestos, v. 2, Produzir para viver: os caminhos da produção não capitalista. Rio de Janeiro: Civilização Brasileira.

SOUZA, Laura de Mello e. 1999. Norma e conflito: aspectos da história de Minas no século XVIII. Belo Horizonte: UFMG. . 1997. Opulência e miséria das Minas Gerais. São Paulo: Brasiliense.

SPIX, Johann Baptist von; MARTIUS, Carl Friedrich Philipp von. 1981. Viagem pelo Brasil: 18171820 [1828]. Belo Horizonte: Itatiaia.

STARLING, Heloisa Maria Murgel. 2004. A estrada de Minas. In: Margem-Márgenes - Revista de Cultura, n. 5 p. 24-35. Belo Horizonte.

SWARBROOKE, John. 2000. Turismo cultural, ecoturismo e ética. In: Turismo sustentável, v. 5. São Paulo, Aleph.

TOFANI, Frederico de Paula. 2004. Os desafios do desenvolvimento turístico sustentável em comunidades tradicionais frágeis. In: Topos - Revista de Arquitetura e Urbanismo, v. 1 n. 2 p. 13-25. Belo Horizonte: NPGAU/UFMG.

\section{Recebido em: 12/03/2008 (1 ${ }^{\text {a }}$ versão) $27 / 03 / 2008$ ( $2^{a}$ versão) \\ Aprovado em: 04/06/2008}

